\title{
HERMENÉUTICA DEL ENEMIGO. SCHMITT Y GADAMER
}

\author{
Víctor Samuel RIVERA \\ Universidad Nacional Mayor de San Marcos
}

\begin{abstract}
RESUMEN. La presente contribución pretende ser una interpretación hermenéutica del pensamiento del concepto de lo político de Carl Schmitt. Situando la reflexión en un fondo de autorreconocimiento histórico en la globalidad, el texto intenta recuperar la distinción dicotómica schmittiana amigo-enemigo como un criterio hermenéutico para la consideración de la propia condición humana en tanto finita, postulando que su desconocimiento pervierte la verdad de la posición del hombre frente al otro. Con recurso a Gadamer y Schmitt, el artículo postula una ontología del diálogo como «claro de la guerran, ontología que sólo es posible recuperando al enemigo en tanto otro humano, un otro cuya dignidad humana descansa en la enemistad. El artículo concluye que el olvido de la enemistad, un síntoma tardío de resistencia de las pretensiones de la modernidad ilustrada, camufla la guerra real y la crueldad contra el otro con una irreal retórica pacifista.
\end{abstract}

\section{Nostalgia hostil}

El enemigo. En un mundo globalizado, regido por un "pensamiento único» o por postreras nociones normativas emancipatorias ilustradas, la enemistad política ha desaparecido. Mientras aquellas se diluyen en las exigencias del mercado y la expansión dominadora de la tecnología, un evento silencioso recorre el saber alegre del pensamiento. El enemigo, el contrario del poder planetario del mercado y la emancipación, ha desaparecido. Por otro lado, es manifiesto que hay una noción característicamente moderna del enemigo, en la que éste adquiere una peculiar dimensión de alteridad narrativa'. En particular, el enemigo de la

"En el sentido de un "otro narrativo", que es el que justifica en la narración las virtudes heroicas y el significado de las acciones del pasado de quien se identifica con la narración. Respecto de 
Ilustración y la ideología emancipatoria, el fondo normativo de la tecnociencia y el mercado, no es otro que el saber tradicional y su concepción de la racionalidad, el obstáculo humano más relevante para el despliegue destinal de la técnica como dominio. En tanto es de la esencia de lo moderno, el enemigo es una dimensión metafísica cuya función es darle sentido progresivo a las metanarrativas emancipatorias, sean liberales, nacionalsocialistas o comunistas ${ }^{2}$. Lo es en el mismo sentido secularizado en que el Demonio constituye su enemistad con la Iglesia en la historia de la salvación, un inevitable corolario de la conocida lectura teológica que hace Karl Löwith acerca de la filosofía moderna de la histo$\mathrm{ria}^{3}$. Es por este motivo que el desvanecimiento epocal del enemigo es el síntoma postradicional de la apoteosis moderna pero, por la misma causa, es también la marca inevitable de su caducidad como proyecto y como destino ${ }^{4}$.

En este mundo "postradicional" los enemigos, o bien no existen, o bien, si se los reconoce, se pretende que carecen de "pensamiento". Quienes disienten del "pensamiento único" de la sociedad globalizada, no importa si representan fuerzas sociales internas a los Estados o sus presuntos pares en el orden internacional, son criminales, psicópatas, corruptos e indeseables, como lo son las alimañas, los insectos o el virus de la peste, con todo el honor y la dignidad morales que se les asigna a esos seres en la autocomprensión de la praxis humana ${ }^{5}$. El enemigo que presentan los medios masivos del mundo globalizado es siempre e inexorablemente un ser irracional, alguien que jamás actúa por convicciones ni representa visiones alternativas del mundo. Sus motivaciones son siempre viles y crueles, sus seguidores meros cómplices. Para él y los suyos no existe trato más generoso ni más apropiado que el ajusticiamiento, que alcanza siempre a evaluar

la modernidad, remito a mi "Rehabilitación del mundo clásico». Yachay, Revista de la Universidad Católica de Bolivia, 2000, n. 17, pp. 31-64.

${ }^{2}$ Dice el célebre sociólogo posmoderno Zygmunt Bauman que "una invención fundamentalmente moderna es la idea de que ciertas categorías de seres humanos no tienen sitio en la 'sociedad buena' que se debe construir, y que ello no se debe a sus fechorías o errores, sino a su incapacidad intrínseca para hacer el bien». Cf. Z. BAUMAN y K. TESTER: La ambivalencia de la modernidad y otras conversaciones. Barcelona: Paidós, 2002 (2001), p. 119.

${ }^{3}$ K. LOWITH: El sentido de la historia. Madrid: Aguilar, 1956 (1949).

${ }^{4}$ Cf. F. FUENZALIDA: Tierra baldia, la crisis del consenso secular y el milenarismo en la sociedad postmoderna. Lima: Australis, 1995.

5 Indica en el mismo sentido Bauman (op. cit.) que «las ambiciones ordenadoras de la modernidad han producido como efecto secundario toda una gama moderna de criminales, cuyo crimen consiste en haber sido acusados". 
vicios, perversiones y desequilibrios personales, pero jamás ideas, valores o versiones comprensivas de lo bueno o lo justo. Su resistencia ante la violencia que se les inflige es siempre fanatismo, jamás sus acciones son heroicas ni sus pautas morales otra cosa que supersticiones o locura ${ }^{6}$. Ni qué decir de sus «ideas políticas». Para el moderno emancipatorio es obvio que no las tienen. Heidegger, aquel pensador cuya adhesión al nazismo no fuera nunca objeto de mea culpa, manifiesta aún en 1946 la nostalgia ética por los soldados alemanes a quienes defiende del mismo tipo de prensa que hoy, y en virtud del desarrollo globalizado de la tecnociencia informativa, haría de su alegato una empresa inviable ${ }^{8}$. No es objeto de discusión la repugnancia por el nazismo. Es objeto de reflexión, en cambio, que hubiera un pensamiento que adviniera del mundo de la técnica para revelar la esencia destinal de Alemania ${ }^{9}$ o, en todo caso, que hubiera alguna vez, en el ocaso de la modernidad, algunos nazis que pensaran. ¿No es eso testimonio, tal vez, de que somos nosotros, los herederos destinales de la narrativa europea de la técnica, quienes hemos sido desalojados del pensar de lo político o, mejor aún, de lo político del pensar?

El enemigo, la amenaza constante de la emancipación, la globalización y el mundo mercantil, ¿̨no será acaso un momento relevante en la comprensión de

6 La caracterización del otro político en el mundo globalizado, creo, es un motivo para sugerir la compilación del debate de prensa sobre la invasión europea a Yugoslavia que hice con Ricardo Vásquez Kunze el año 2000: Cosmopolitas y soberanistas. Lima: ICP, 2000.

7 Difícilmente es un mea culpa la entrevista de 1966 a Der Spiegel, y menos esa suma de disculpas que son sus precisiones sobre el periodo del rectorado. En este sentido, más sobrio parece el mero acatamiento a la consistencia moral que es el dictamen comprensivo de Ernst Nolte en su Heidegger, politica e historia en su vida y pensamiento. Madrid: Tecnos, 1998 (1992). Respecto de Heidegger, cf. La autoafirmación de la universidad alemana; El rectorado, 1933-1934; Entrevista del Spiegel. Madrid: Tecnos, 1996.

${ }^{8}$ Cf. M. HeidegGer: "Carta sobre el humanismo" (1946). En: Hitos. Madrid: Alianza Editorial, 2000, p. 279. Dice allí Heidegger primero que «la relación de Hölderlin con lo griego es algo esencialmente diferente» de la concepción de la racionalidad práctica heredada de las narraciones emancipatorias "del humanismo". Agrega luego que "por eso los jóvenes alemanes que sabían de Hölderlin pensaron y vivieron frente a la muerte algo muy distinto de lo que la opinión pública hizo pasar por el modo de pensar alemán». Al parecer, el mérito de "lo alemán» no había sido borrado por la derrota de 1945, por lo menos no si se piensa en la supervivencia moral de Hölderlin como tarea, a cuyo poema "Mi Patria» está aludiendo Heidegger.

9 Dice Heidegger que «lo 'alemán' no es algo que se le dice al mundo para que sane y encuentre su salud en la esencia alemana, sino que se le dice a los alemanes para que, partiendo de su pertenencia destinal a los pueblos, entren con ellos a formar parte de la historia universal». ¡Vaya si entraron! Cf. ibid., p. 278. 
lo humano? ¿No hay acaso una dimensión hermenéutica del enemigo cuyo silencio constituye un despojo de nuestra propia esencia comprensiva? Por otro lado, el desvanecimiento del enemigo no significa su muerte, pues las categorías de la comprensión humana son inmortales. De hecho, constituyen nuestro único monumento eterno. Si el enemigo ha desaparecido para nuestra autocomprensión contemporánea sobre la base de una lectura emancipatoria de nuestro envío, el diagnóstico que parece imponerse es sólo uno: El enemigo está allí siempre presente, olvidado bajo los frágiles tiestos de nuestra conciencia endeble de la apoteosis moderna, quizá aplastado como un ser vil en los escombros insondables de Arabia. Tal vez, quebrando algo de nuestra fragilidad, encontremos allí esperando al enemigo, con toda la dignidad, el honor y la grandeza que concedemos a quienes podemos llegar a reconocer como nuestros necesarios.

\section{¿Emancipados del enemigo?}

Curiosamente, uno de los más importantes defensores de la relevancia de la idea de «enemigo" para la comprensión de lo político que tuvo el siglo XX, Carl Schmitt, había diagnosticado hace ya casi una centuria en su El concepto de lo politico, que lo que podemos considerar hoy el consenso global del upensamiento único" respecto a que el enemigo ha desaparecido no es sino una de las improntas más nefastas del pensamiento emancipatorio liberal en su eventual primacía planetaria. En efecto, el desarrollo del ideal «emancipatorio» de las ideologías ilustradas implica, según Schmitt, no sólo la supresión de la idea del enemigo políicico - que bien podría trocarse en una dimensión conceptual diferentesino que acarrea en su extremo la incomprensión moral de la praxis involucrada en la idea misma de lo político. Para no entrar en extravíos, definamos primero a lo político como una negociación conflictiva entre grupos humanos cuyo margen limítrofe (y sin duda indeseable) es la guerra o la violencia civil. Si la perversión del "pensamiento único» reduce al enemigo a una alimaña, evidentemente no es porque hayamos llegado a alcanzar el margen utópico de la supresión emancipatoria de la violencia, como, por ejemplo, ocurre en su versión kantiana. Lo que parece ocurrir es que nuestro consenso consiste en que el enfrentamiento de intereses comunales con un otro se realiza por algún tipo de negociación privilegiada que excluye la enemistad, esto es, el trasfondo hermenéutico de la violencia. Creo que es a esto a lo que llaman los modernos el presunto carácter "reflexivo" de las sociedades contemporáneas democráticas, donde los diferendos son idealmente resueltos en mecanismos institucionales preestablecidos. 
No es un problema conceptual que exista una narrativa de la autoimposición del "pensamiento único" como ideal emancipador. Tampoco, incluso, que carezca de fundamento. El problema es que la violencia subsiste, que la enemistad, pues, no ha desaparecido. A eso el ilustrado, Javier Muguerza, por ejemplo, responde sólo exigiendo más ilustración ${ }^{10}$.

En la idea de "reflexión" está encerrada una convicción (infundada): que el margen comprensivo de la diferencia se clausura en una dinámica donde el otro nunca puede ser otro completamente, de tal modo que el conflicto limítrofe ha sido ocupado por un abismo de vacío, un vacío hermenéutico que daría por sentado que el problema general de la violencia no es un extremo de la cuestión de visiones comprensivas en conflicto, sino una imperfección subsanable del cosmopolitismo que habría que corregir, cual es el caso de la nueva Martha Nussbaum (no más la aristotélica de La fragilidad del bien), por la educación cosmopolita ${ }^{11}$. Una forma benévola de comprender lo anterior sería diagnosticar que el otro es simplemente aquel que aún no ha alcanzado la mayoría de edad, para lo cual habría que "reeducarlo" en la in-diferencia, algo que Gonzalo Gamio ha llamado una "paideia democrática» y que - no puedo interpretar esto de otro modo - habría que aplicar a los pueblos o al pueblo desde la luminosidad del saber del experto en política o humanidad ${ }^{12}$. Curiosamente el abismo de vacío no es otro que la ausencia de dignidad humana (el inculto democrático aún no es tan humano como el experto). Esto nos lleva a la conclusión de que la posición efectiva, no imaginaria del disidente, lleva consigo la demanda moral inapelable por su exterminio en tanto otro, por la realización moral de su vacío ${ }^{13}$.

${ }^{10}$ Cf. por ejemplo su ensayo "Kant y el sueño de la razón», en C. THIEBAUT (ed.): La herencia ética de la Ilustración. Barcelona: Crítica, 1991.

1 Cf. M. Nussbaum: "Patriotismo y cosmopolitismo", en M. Nussbaum (comp.): Los limites del patriotismo, identidad, pertenencia y ciudadanía mundial. Barcelona: Paidós, 1999 (1996).

12 Acúdase a los ensayos de G. Gamio en V. SANTUC, S. J. et alii: Democracia, sociedad civily solidaridad. Lima: Instituto de Ética y Desarrollo de la Escuela Superior Antonio Ruiz de Montoya, 1999. Curiosamente, a la par de desarrollar la idea ilustrada de "educar" en los valores ilustrados, Gamio es un grave recusador del saber esotérico de los expertos, sin notar, al parecer, que sólo un «experton en techné política puede arrogarse el derecho de corregir a los demás con una "educación democrática», supongo, por no ser «democráticos», o sea, ser unos menores de edad no ilustrados por el saber arcano del experto quien, curiosamente, habría de ser reconocido en el autor.

13 Cf. C. Schmitr: El concepto de lo político. Madrid: Alianza, 2002 (1932). Dice Schmitt, refiriéndose a las declaraciones postginebrinas sobre la "criminalización del agresor" (p. 131): "Ahora el derecho internacional se trata de definir como hecho criminal porque hay que convertir al 
No poder ver al enemigo sería lo mismo que la obligación moral de no verlo y, por qué no, de suprimirlo ${ }^{14}$. Para el efecto, la modernidad liberal contaría, habremos de añadir, con la base de un programa de dominio que, habiendo invadido los fueros de la racionalidad práctica desde la racionalidad de la tecnociencia, como ya habrían diagnosticado desde otro ángulo Horkheimer y Adorno ${ }^{15}$, habría impuesto en ella un asiento de certeza que tiene la consecuencia hermenéutica de un autodespojarse esencial de la presencia de un otro, en el sentido psicoanalítico de una patología narcisista que genera una incapacidad para percibir al otro como otro realmente ${ }^{16}$.

En las circunstancias que anteriormente he esbozado, la razón de por qué el pensamiento moderno, y el republicanismo liberal globalizado en particular, habrían disuelto la noción de enemigo no sería otra que el vacío hermenéutico para todo otro que, justamente por esa causa, es revertido en su presencia moral como un mero mal, en una incomodidad ininterpretable en términos de pensamiento y que es extraña a toda condición posible de diálogo ${ }^{17}$. Me atrevería a decir: como es de incómoda e irrelevante la presencia de las ratas o las moscas con quienes, sin duda, no dialogamos antes de exterminarlas. El enemigo, sin embargo, no ha desaparecido. Lo que ha ocurrido con él es el evento de su desinvestidura humana. Ahora bien, el desalojo comprensivo del enemigo, pensado desde el punto de vista de la hermenéutica, significaría no otra cosa que el olvi-

enemigo en un delincuente». ¡Si no sabrán de eso los oponentes del "pensamiento único»! En Londres o Ámsterdam los contestatarios mueren misteriosamente asesinados. Como pueblos, son prohibidos en sus tradiciones, como ocurre en Francia. Fuera de Europa los países obstáculo son sometidos a invasiones militares, bombardeos y vejámenes, algo que el presidente de Estados Unidos mientras redacto este ensayo, Georges Bush, llama la «justicia infinita».

14 «En la actualidad las guerras son necesariamente de intensidad e inhumanidad insólitas, ya que van más allá de lo político y degradan al enemigo al mismo tiempo con categorías morales y de otros tipos, convirtiéndolo así en el horror inhumano que no sólo hay que rechazar sino que hay que aniquilar definitivamente» (ibid., p. 66). Schmitt estaba pensando seguramente más en el desastrado Reino de Prusia que en los enemigos raciales semitas de Hitler.

${ }^{15}$ CF. M. HORKHEIMER y T. ADORNO: Dialéctica de la Ilustración, fragmentos filosóficos. Madrid: Trotta, 2001 (1969).

16 En el sentido de un problema de ausencia del otro en la «fase del espejo», en el lenguaje de Jacques Lacan. Agradezco a Rosa María Normand las innumerables tardes de conversación sobre Jean-François Lyotard, y los psicoanalistas Lacan, Kohud y Rosenfeld, sin las cuales alguna parte útil de este trabajo habría sido imposible.

17 C. C. SCHMITT: La Dictadura, desde los comienzos del pensamiento moderno de a soberanía hasta la lucha de clases proletaria. Madrid: Alianza Editorial, 1999, cap. III. 
do de la diferencia como realización de la racionalidad. La diferencia como idea de fractura, como idea de disenso, consiste fundamentalmente en el acontecer abierto que es el lenguaje. Y el lenguaje se abre a lo diferente sólo cuando hace lugar a lo impensado, cuando permite el acontecer de lo otro en tanto que realmente otro. En este sentido lo político como apertura en el lenguaje no sólo es y debe ser pensamiento, sino también historia ${ }^{18}$. Hay una dimensión en el olvido del enemigo por la cual el espacio dinámico del pensar como lógos, como lenguaje que acontece como apertura de historia, ha diluido un elemento fundativo de la experiencia misma del pensamiento político en tanto político: La condición para desconocer al otro presupone una autocomplacencia en el reino de los fines morales, lo que podemos considerar una teleología política narcisista. Sólo una comunidad infinita de amigos puede carecer de enemigos. Pero en tal comunidad, como bien nota Schmitt, lo político ha muerto ${ }^{19}$. Hay que agregar que esto es posible desde el punto de vista de la interpretación de la praxis como forma de racionalidad únicamente si no es factible ya poner en cuestionamiento la marcha teleológica de la acción humana. Pregunta: ¿Es incuestionable acaso el presente planetario? ¿Es inimaginable su cambio?

Si la idea emancipatoria es un ideal inapelable puede ser por dos motivos. Se puede tratar de un acto de fuerza ontológico de imposición planetaria, por ejemplo, "la voluntad de voluntad" afincada en la técnica de las comunicaciones y el mercado, en cuyo caso es algún tipo de ejercicio de la tiranía cual, como adelanto, sería la perspectiva más natural partiendo de la reflexión de Gadamer sobre el carácter universal de la lingüisticidad. Se puede tratar también del desvelamiento de una necesidad epocal, de una dimensión irrenunciable de la autocomprensión humana; el destino del hombre se confinaría a la renuncia a la reflexión sobre los fines y

${ }^{18}$ En mi modesto concepto, este es el ángulo desde el cual abordar la cuestión posmoderna del disenso, que ha sido soslayado por Habermas en su debate. Justo lo único que cuenta. Cf. J. HABERMAS: "Concepciones de la modernidad", en La constelación posnacional, ensayos politicos. Barcelona: Paidós, 2000 (1998).

19 En este sentido dice Schmitt: «Si la totalidad de los diversos pueblos, religiones, clases sociales y grupos humanos en general llegara a unirse y acordarse hasta el extremo de que hiciese imposible e impensable para todo tiempo una guerra civil; si, en consecuencia, desapareciese hasta la eventualidad de la distinción entre amigo y enemigo, en tal caso [estaríamos] libres de política, pero no habría ya ni política ni Estado. Yo no sé si semejante Estado se producirá alguna vez, ni cuándo [y] sería una ficción poco honrada darlo por existente y una equivocación que se desharía por sí sola" (C. SCHMITT: El concepto..., op. cit., p. 83). Los comentarios sobran. 
la mera resignación maquinal al fundamento. En todo caso, aceptemos provisionalmente como un hecho el consenso «único» del fin de la enemistad. La principal consecuencia de esto es el carácter inexorable de los fines; lo que, traducido en otros términos, significa que junto con el enemigo se ha desvanecido también una idea básica para la comprensión de la acción política: que es la postulación, bajo el modo del alegato, de la excelencia y la ocasión de un cierto régimen, esto es, la idea de que detrás del ser efectual de un régimen político subyace una reflexión discursiva frente a su necesidad, dentro de una gama variable de regímenes cuya excelencia propia ha sido desestimada. La vivencia del ser de lo político en un determinado régimen supone el constante alegato en su favor, una actividad cuya esencia política descansa, precisamente, en el entrañamiento con la actividad del disiden$\mathrm{te}^{20}$. Da lo mismo si el que disiente es un enemigo internacional o local; la presencia de tal enemigo es el presupuesto de los alegatos en favor del régimen, y más aún si se trata de algún tipo especial en el que la praxis política fuera la de una amistad infinita. Con el "pensamiento único" estamos ante el caso de una uinfinitud" carente de enemigo, que se ha vuelto incapaz de reconocer su propia finitud, bien porque pretende que no existe, bien porque se la ha olvidado. Una vez más, concluiremos que un régimen sin enemigos puede (quizá) ser alguna forma de convivencia humana aún impensada, pero en él la idea del pensamiento de lo político habrá desaparecido y, con el pensamiento, también lo político mismo. Según los indicios de la práctica del "globalismo", lo más que requiere el consenso del universo liberal es la confirmación de su unanimidad. La forma privilegiada es la imposición liviana de la cultura del mercado a través de la educación "ćivica»" ${ }^{21}$. La invasión militar, la represión o la dominación mediática no merecen detalles.

Volvamos a la perversión de la lógica emancipatoria republicana. El liberal republicanista, sea rousseauniano o kantiano, tiene siempre a identificar, piensa

${ }^{20}$ Curiosamente, la teoría de Rawls del consenso traslapado, que sería la justificación política del consenso liberal, no estaría escrita para entrar en diálogo reflexivo genuino en un contexto de regímenes con excelencias rivales que argumentasen entre sí, cada una alegando en su favor. No es de extrańar que apele Rawls al rechazo de la "metafísica" (o sea, el pensamiento) como una condición para alegar en favor del consenso liberal. En ese caso, por cierto, el alegato se declara válido sólo para ciudadanos que participan efectivamente del consenso de las modernas democracias que viven en una economía de mercado. ¿Para qué - me pregunto- querrían tales ciudadanos un alegato para justificar algo que ya aceptan? Cf. J. RAWLS: Liberalismo politico. México: FCE, 1995 (1993), pp. 36 y ss. De igual modo, cf. A. Wellmer: Finales de partida, la modernidad irreconciliable. Madrid: Cátedra, 1996 (1993), pp. 183 y ss.

${ }^{21}$ Como en el artículo de Nussbaum antes citado. 
Schmitt, la esfera de lo político con un cierto modelo de moralidad que, para usar un lenguaje que nos es más cercano, adquiere una dimensión perentoria en sí misma inexplicable, y a la que tenemos acceso narrativo sólo en una historia en la que el modelo monológico de la tecnociencia se ha convertido también en el molde de la verdad de la autocomprensión humana ${ }^{22}$ y donde los técnicos o los científicos son los sabios filósofos de una república que ha automatizado la adhesión a los fines. La emancipación, como teleología y como práctica, coincidiría en su expansión con el mero despliegue operativo de la tecnociencia, y su verdad, como no podría ser de otro modo, sería una ciega solidaridad con sus fines. En este sentido, la "verdad» narrativa del despliegue de la emancipación se distingue porque su relación con el enemigo consiste en sí misma en el rechazo hermenéutico.

En el universo de la política y lo político, la "verdad» es un saber impositivo y perentorio, que desconoce las diferencias de intereses reales del amigo y el enemigo, y se plasma como un obstáculo hermenéutico para la comprensión humana. Creo que es en este sentido que hay que tomar las notas de Hans-Georg Gadamer quien, en múltiples ocasiones, ha intentado mostrar que la lógica del comportamiento emancipatorio ilustrado involucra una concepción de lo político cuyo extremo no sería otro que el de una racionalidad puramente administrativa, en la que la cuestión de los fines propiamente humanos de las comunidades políticas se habría vuelto irrelevante para los detentadores ilustrados del poder. La "verdad" del mercado o de la "democracia" habrían descartado la reflexión diferenciada ${ }^{23}$. Los fines de tal poder administrativo se habrían hecho destinales porque, divorciados del ámbito del pensamiento, habrían devenido el soporte de una divinidad aristotélica indiferente. En términos de Rawls, habrían descartado la cuestión "metafísica" acerca de los fines de la vida buena para adscribirse, ya acríticamente, al inevitable molde institucional emancipatorio. El lema sería: "política (¡administrativa?), no metafísica» ${ }^{24}$.

22 Cf. este diagnóstico en H.-G. GADAMER: «Lenguaje y comprensión» (1970), en Verdady método II. Salamanca: Ediciones Sígueme, 1992 (1986), pp. 181 y ss.

${ }^{23}$ Cf. el apólogo a La teoría de la acción comunicativa de Habermas hecha por A. Wellmer ("Razón, utopía y la dialéctica de la ilustración», en A. GIDDENS et alii: Habermas y la modernidad. Madrid: Cátedra, 1994).

${ }^{24}$ Cf. el famoso artículo del último Rawls, que pretende librarse de las objeciones de los comunitaristas, neoaristotélicos, postwittgensteinianos o pragmatistas como el Rorty de la década de 1980 , aduciendo que nuestro "consenso" en las «sociedades democráticas" excluye el interés por 
Creo que es manifiesto que lo anterior es el caso cuando nos enfrentamos a la idea de que existe un "pensamiento único» o de que el fenómeno de globalización implica cosas tales como la "globalización de la justicia" o la "globalización de la política», meros apéndices de una irrenunciable globalización del mercado. Si estamos en lo correcto, y estas expresiones revelan el olvido del enemigo como evento, no sólo nos estaríamos encaminando de hecho a un mundo políticamente administrado, en el que la reflexión humana estaría ausente de la autocomprensión del ser de las colectividades humanas reales, sino a algo aún más grave, a un horizonte de mundo donde la diferencia, la grieta ontológica para el reconocimiento del acontecer destinal del misterio, se habría desvanecido, pace Lyotard. El pensamiento, como apertura lingüística para el destino, se habría resignado en la paz de los cementerios. $\mathrm{O}$ en la no menos paradójica paz comercial de los supermercados.

La comprensión masiva del mundo posmoderno representa en los hechos la insignificancia conceptual del disenso o, como hacen Richard Rorty y John Rawls, su enclaustramiento en la cárcel o el manicomio, con la compañía insigne de Nietzsche y San Ignacio de Loyola ${ }^{25}$. Como sabemos, el reconocimiento de esta postura llevó a Rorty a desplazar el rol del pensamiento a una actividad estética marginal, a postular algo tan incomprensible como comprender la actividad filosófica (es imposible aquí usar la palabra "pensamiento») como fomento cultural de la frivolidad en las sociedades de "pensamiento único" ${ }^{26}$. El hecho es que la apelación ética a la excelencia del propio régimen es hermenéuticamente incomprensible sin la presencia de un otro. Es más, como se desprende de las conclusiones de Rorty, el alegato en favor del régimen en ausencia de un otro se vuel-

el debate conceptual como disidencia. Habrá que darle la razón a Rawls. Sin duda, lo suyo es politica pero no "filosofia». J. RAWLS: "La justicia como equidad: Política, no metafísica" (1985); versión traducida en La Politica, revista de estudios sobre el Estado y la sociedad, n. 1, 1996, pp. 22-46.

${ }^{25}$ Cf. el artículo de Rorty en que se comenta el anterior de Rawls (R. RORTY: «La prioridad de la democracia sobre la filosofía», en Objetividad, relativismo y verdad. Barcelona: Paidós, 1996 [1991]).

26 Dice Rorty: “Puedo formular una aclaración para corregir el aspecto de frívolo esteticismo que estoy adoptando ante las cuestiones filosoficas tradicionales. Se trata de que, tras esa frivolidad, hay un fin moral [...]. Ayuda a hacer a sus habitantes [del mundo] más pragmáticos, más tolerantes, más liberales, más receptivos a las apelaciones de la razón instrumental" (ibid., p. 263). ¡Las apelaciones de la razón instrumental! Habría que decirle eso a los marginados, malnutridos y desempleados de las megápolis de América Latina, a ver cómo reaccionan. 
ve un ejercicio completamente inútil de persuasión. La apelación política es siempre el reclamo y la respuesta de un tipo de excelencia en cuyo diálogo con otro se hace lenguaje. En vano se esmeran los modernos invocando la razón comunicativa o el consenso traslapado si, literalmente, la reflexión coincide con la frivolidad. La supresión de la categoría de enemigo -agreguemos: la muerte también del amigo- trastoca la esencia de lo político en una suerte de voluntad total de resultado de un agente solitario cuyo télos puede ser sólo el éxito, no más el pensamiento. Sin "otro" que sea o pueda ser lenguaje, la mera idea de la realidad hermenéutica misma ha colapsado en un encierro narcisista cuya única política es la eficiencia. Ahora bien, ese "otro" cuya ausencia configura el horizonte tardomoderno de la globalización en el horizonte de lo político es el enemigo. Sin la noción del enemigo, la política y lo político dejan de ser genuinos ámbitos de disenso, ocupando su lugar una oclusión hermenéutica que reduce el universo de la praxis, como estamos intentando esbozar, al quehacer del administrador social o del experto en "política»".

Nuestra postura es que urge ir en busca del otro político, para que el enemigo, aquel que siendo otro no es ni una rata ni una mosca, sea capaz de regresar desde el olvido narcisista de cuya imagen fuera borrado en alguna parte de la infancia de la modernidad. Si es real que el otro político se ha desvanecido, y con él se ha eliminado también uno de los elementos fundamentales del interés por la política como praxis, que es la relación hermenéutica con la diferencia, no es vana nuestra empresa. Queremos recuperar al enemigo cuya ausencia ha sentenciado la teleología narcisista de la tecnociencia. Queremos, pues, volver a pensar, y para ello habremos de buscar el reconocimiento humano del enemigo. Pero ¿cómo entender al enemigo? ¿Cuál es el rol del enemigo en la autocomprensión humana? Habrá primero que esbozar la dicotomía amigo-enemigo tal y como la sugiere Carl Schmitt, para luego reinterpretarla sobra la base de las críticas de Gadamer a la idea de emancipación.

\section{Marte, dios de la guerra}

No es tan simple entender la noción de «enemigo" que estamos tomando de Carl Schmitt, en particular porque la hemos sustraído de su medio inicial. Que-

${ }^{27}$ Cf. Z. BAUMAN: En busca de la politica. México: FCE, 2001 (1999), especialmente pp. 33 y ss. 
remos hacer con ella una versión desconstructiva que se yerga como hermenéutica de lo político. Se trata de la urgencia ante la necesidad de explicarnos la criminalización moral de los enemigos en una tardomodernidad dominada por el saber de la tecnociencia. Como se sabe, la idea del enemigo, tal y como la hemos sustraído del libro de Schmitt El concepto de lo político, constituye de alguna manera la recuperación y el desarrollo de la concepción maquiavélica de lo político como la oposición dicotómica entre amigos y enemigos ${ }^{28}$. En este sentido, la idea de schmittiana del enemigo como categoría política forma parte de un conjunto de distinciones orientadas hacia una variante de la comprensión moderna de la racionalidad práctica, ligada a la comprensión del modelo de orden mundial de Estados nacionales consolidado en la Paz de Westfalia. Sin embargo, la intención expresa de Schmitt no es hacer una aclaración conceptual ni tampoco adscribirse a una cierta corriente peculiar de concebir la naturaleza de lo político, sino de hacer algo que resulta ser una anámnesis de lo que podríamos llamar nuestra precomprensión de lo político mismo sobre el fondo opaco de la modernidad. Para comenzar, la idea de "enemigo" en Schmitt se presenta como una categoría hermenéutica primitiva, un presupuesto fundamental sin el cual es imposible acceder a la comprensión de lo político en general. Ahora bien, algo que hemos omitido hasta ahora es que en realidad la noción de enemigo sólo funciona dicotómicamente. Es parte de una distinción bipolar que contrapone el enemigo al "amigo". Habría que agregar que la distinción amigo-enemigo, en términos lógicos, constituye para Schmitt una condición necesaria para concebir lo político mismo, de tal modo que su supresión o su olvido concluye en la desnaturalización o la perversión de la praxis política, la imposibilidad de pensar la praxis políticamente. Es justamente un ejemplo de esto el trato inhumano del enemigo que es manifiesto en las postrimerías de la modernidad por quienes son sus detentores o abogados conceptuales. Afirma literalmente Schmitt: «La distinción política específica, aquella a la que pueden reconducirse todas las acciones y motivos políticos, es la distinción de amigo y enemigon" ${ }^{29}$.

Ahora bien, hay ciertas características de tipo hermenéutico que están presupuestas en la dicotomía antes mencionada. Lo político, propiamente hablan-

${ }^{28}$ Cf. C. SCHMITT: El concepto..., op. cit., pp. 93 y ss. Cf. asimismo E. HeRNANDO: Pensando peligrosamente: el pensamiento reaccionario y los dilemas de la democracia deliberativa. Lima: PUCP, 2000, pp. 164 y ss.

${ }^{29}$ Cf. C. SCHMITT: El concepto..., op. cit., p. 56. 
do - definiré esta vez yo-, sólo existe cuando hay un plano de lectura de los propios intereses en los que estos significan un conflicto con los intereses de un otro, en el que esos intereses se identifican como aquello en contra de lo cual hay una comunidad de quienes son nuestros amigos. En primer lugar, hay que subrayar que se trata de una noción que incluye - tal vez a pesar de Schmitt - una versión hermenéutica de una racionalidad práctica que está comprometida normativamente. En efecto, el uso del concepto de lo político, cuando está adecuadamente contextualizado en un marco de intereses concretos en rivalidad con un otro concreto, implica la idea de una pertenencia comunitaria sustantiva cuya identidad está necesariamente basada en un trasfondo vinculante, un trasfondo que exige compromisos correlativos de tipo claramente moral como la lealtad y la solidaridad, y que demanda el florecimiento de virtudes como la valentía, la generosidad o la clemencia. ¿Con quién ser clemente, si no se lo es con el enemigo? Hasta podemos señalar que hay algunas virtudes morales que son específicas de la dicotomía schmittiana, como notoriamente es el caso del heroísmo, incluso si, como seguramente se me objetará, se trata de una virtud prescindible.

Como ha notado de modo particularmente claro el sociólogo Zygmunt Bauman, si pensamos en la dicotomía amigo-enemigo ${ }^{30}$ hay una manifiesta prioridad hermenéutica en la identificación del enemigo sobre el amigo, dado que el reconocimiento de la enemistad es, para hablar postwittgensteinianamente, el "criterio" de la identidad con el amigo ${ }^{31}$. Esto mismo ha sido observado también por Gadamer, de un modo tal que la interpretación del enemigo está atada a la experiencia misma del carácter lingüístico de la racionalidad y es, depurada del delirio metafísico ilustrado por la "verdad", punitivo e inhumano, una condición elemental para la convivencia humana como apertura de horizonte y, con Hei-

${ }^{30}$ Cf. Z. BAUMAN y K. TeSTER: La ambivalencia..., op. cit., especialmente caps. 3 y 5.

${ }^{31}$ Dice C. Schmitt (El concepto..., op. cit., p. 93): «Lo que la distinción proporciona no es una definición exhaustiva de lo político, ni una descripción de su contenido, pero sí una determinación de su concepto en el sentido de un criterion. Aunque difiero rotundamente de su interpretación, habría que citar por su difusión en América Latina el ensayo de Atilio Boron y Sabrina González: "¿Al rescate del enemigo? Carl Schmitt y los debates contemporáneos de la teoría del Estado y la democracia", en A. BORON (comp.): Filosofia política contemporánea, controversias sobre civilización, imperio y ciudadania. Buenos Aires: Clacso, 2002, especialmente pp. 144-148. Sostienen los autores que según Schmitt (j!) "la política se convierte en la lucha de unos contra otros» y que "fuera de tal criterio (amigo-enemigo) no hay nada más" (p. 145). Espero que el lector de este articulo no se lleve la misma impresión. 
degger, del pensamiento mismo ${ }^{32}$. El significado de esta observación para nuestro propósito es que ratifica que el vínculo políico es esencialmente una relación de compromiso, aunque su característica propia sería negativa, ya que tiene lugar sólo y únicamente cuando hay un reconocimiento previo del aspecto conflictivo de los intereses que se disputan con otro. Aunque es una relación que implica la idea de comunidad, no opera sobre la presunción positiva de que la comunidad que se reconoce frente al enemigo deba imponerse a sus pares, sino sólo la de que hay un fondo (contingente) de diferencia que aparece como carácter destinal para quienes hacen "nosotros" en la narrativa respectiva. Esto, en buena cuenta, es parte de la dimensión irrenunciable de compromiso ético con la pertenencia, desde la cual la violencia aparece como una herencia destinal que en gran medida es pauta de saber quiénes somos y cuál es nuestro envio ${ }^{33}$. Obviamente, la razón de por qué hay prioridad hermenéutica del enemigo y no es al revés y el reconocimiento del amigo no prevalece como criterio de la diferencia es justamente porque la idea de la amistad se funda en la investidura del diferente quien, aunque sea de modo potencial, es enemigo. A esto hay que agregar que la distinción schmirtiana amigo-enemigo sólo tiene una relación accidental con la virtud moral de la amistad, pues hay que insistir en que se trata sólo del establecimiento de un marco de comprensión hermenéutica de la acción política, no de la descripción de un cuadro moral, y mucho menos de la definición de un óptimo ético, que es lo que hacen, dicho sea de pasada, los modernos emancipadores.

La oposición amigo-enemigo estaría concebida, reinterpretando gadamerianamente a Schmitt -como hemos venido haciendo no sin cierto desenfado-, al modo de un trascendental hermenéutico para acercarse como intérprete de los

32 "Lo negativo o lo privativo tiene evidentemente la ventaja", dice Gadamer (aludiendo al problema de hacer un único "orden" mundial, más o menos modelado según el emancipatorio "pensamiento único"), "de que se impone por sí mismo como objeto de negación y de eliminación a nuestra voluntad de cambio y cobra así un perfil. Siempre es más fácil definir el concepto de desorden para eliminarlo, y obtener así un sentido diferenciado de orden per contrarium». Cf. H.-G. GADAMER: "Sobre la planificación del futuro" (1966), en Verdad y Método II, op. cit., p. 154.

${ }^{33}$ A este respecto, resultan altamente relevantes las apreciaciones de MacIntyre sobre la comprensión necesaria de la diferencia como parte de la condición humana, en tanto que opuesta a esquemas comprensivos universalistas y totalizadores propios de la modernidad incluyendo, claro está, el alegre saber del "pensamiento único". Cf. A. MACINTYRE: "Relativism, Power, and Philosophy", en K. BAYNES et alii (comp.): After Philosophy, End or Transformation? Cambridge: MIT, 1996 (1987). 
conflictos (políticos), esto es, como un esquema básico de comprensión de aquellas diferencias que consideramos políticamente relevantes. De hecho, no es enfático afirmar que la oposición amigo-enemigo es indesligable de cualquier noción de conflicto aplicable a comunidades humanas. Como concepto, como punto de partida, es sólo un alcance de la precomprensión de la praxis política; carece de contenido específico y, fuera de circunstancias que le otorguen significado, es una idea vacía, como desde Aristóteles sabemos que lo es la de todo trascenden$\mathrm{tal}^{34}$. No está demás recordar que el enemigo schmittiano puede ser objeto de nuestro aprecio, de nuestra admiración, e incluso de nuestra amistad ética. Las últimas son relaciones morales. La primera es una categoría política.

Pero volvamos a la idea postwittgensteiniana de entender el concepto del enemigo en Schmitt como un "criterio" del amigo. Como es bien sabido, un "criterio" en el sentido de ese término en el segundo Wittgenstein es el equivalente posmoderno de la esencia. No es la esencia como rasgo invariable, sin duda, sino un medio de identificación, un indicador o un síntoma ${ }^{35}$ y, por consiguiente, admite todas las opacidades que pueden esperarse de ese concepto y que es el caso de otras dicotomías hermenéuticas análogas, como la de lo bello y lo feo para la estética o la de lo bueno y lo malo para la experiencia de lo ético, casos citados por Schmitt ${ }^{36}$. Independientemente de que lo haya o no percibido así Schmitt, un criterio wittgensteiniano carece de carácter definitorio, es frágil y variable, puede diversificarse en los ámbitos, aplicarse complejamente de diversas formas a la misma persona o a grupos diferentes en un mismo sentido, carece de carácter perentorio y puede aplicarse o disolverse de forma abierta en el ámbito propio de su origen que, al ser indeterminado por su carácter trascendental, se acoge al horizonte de comprensión dentro del que es usado. Quiero decir: La noción de lo político está subordinada a las condiciones (arbitrarias y presentes sólo narrativamente) en las que grupos diferentes presentan conflictos

${ }^{34}$ Esto está muy claro en el propio Schmitt (El concepto..., op. cit.): «Es una distinción autónoma, pero no en el sentido de definir por sí misma un nuevo campo de la realidad, sino en el sentido de que ni se funda en una o varias de las otras distinciones ni se la puede reconducir a ellas». Sobre Aristóteles, cf. Etica a Nicómaco, A 4, 1090 b 20.

35 Para una introducción a la cuestión del uso wittgensteiniano de "criterio" sugiero A. GARClA SUÁREZ: La lógica de la experiencia. Wittgenstein y el problema del lenguaje privado. Madrid: Tecnos, 1976, cap. VII.

${ }^{36}$ Cf. C. SCHMITT: El concepto..., op. cit., p. 56. Mutatis mutandis, es la misma aproximación de Gadamer en «Sobre la planificación del futuro», de 1966, que hemos citado arriba. 
cuyo margen limítrofe es la violencia y que, por ende, no es en sí misma una noción "violenta". Aunque Schmitt no había percibido con suficiente claridad este detalle, y le haya concedido más relevancia al hecho sociológico de que la enemistad va acompañada por sentimientos agresivos que suelen ser intensos ${ }^{37}$, nada de esto invalida la evidencia hermenéutica fundamental de que la noción de "enemigo" implica un tipo de aproximación con el enemigo real que es mucho más abierta, más generosa y más moralmente relevante incluso que la del amigo, al menos del amigo político, cuya comprensión es la recíproca del enemigo. Es verdad que también Schmitt intenta recuperar a su manera la distinción romana entre hostis e inimicus, señalando la diferencia entre la rivalidad política y el conflicto personal ${ }^{38}$, pero lo hace para insistir en que la diferencia ha sido perdida en la modernidad en lo que, sin duda, no le falta algo de razón. Pero eso no se debe a una suerte de simplificación lingüística, sino a un acontecer destinal del Occidente en cuyo fin emancipatorio el exterminio del enemigo ha adquirido carácter precomprensivo, reemplazando y olvidando la concepción más originaria del reconocimiento de la hostilidad, cuyo descuido es una pérdida para la comprensión del hombre en su finitud.

Como, creo, va siendo manifiesto de mi argumentación, en realidad identificar al enemigo es sólo un criterio de rango elevado dentro de una concepción de la racionalidad práctica más amplia que abarca dimensiones sustantivas previas de tipo normativo y competencias prudenciales necesarias, como el desarrollo moral del sentido de la aplicación del criterio, por ejemplo, y en ese sentido comprehende el aspecto deliberativo propio de una concepción aristotélica o clásica de la racionalidad ${ }^{39}$. En cualquier caso, identificar al enemigo es una actitud hermenéutica que se asienta en el horizonte de las virtudes correlativas a la relación de enemistad que he subrayado arriba, con lo que implica no sólo que puede traslaparse con la amistad privada, sino además acarrea - pace Maquia-

${ }^{37}$ C. C. SCHMITT: El concepto.., op. cit., pp. 58 y ss.

38 Ibidem.

39 En el mismo sentido en que Alasdair MacIntyre replantea el fondo hermenéutico del fin de la modernidad como un campo de conflicto eventual de racionalidades, esto es, de aproximaciones comprensivas genuinamente diversas. De hecho, recuperar la enemistad en su dimensión humana supone no sólo afectar la comprensión narrativa del "pensamiento único", sino rescatar también la dimensión reflexiva del pensamiento, exigiéndole, así de paradójica es la historia humana, emanciparse de la emancipación. Cf. A. MACINTYRE: Whose Justice, Which Rationality? Notre Dame: University of Notre Dame Press, 1988. 
velo- tanto el desarrollo de las propias virtudes como el cultivo general de la excelencia en el sentido teleológico aristotélico. Hay buenos enemigos y malos enemigos, hay enemigos nobles y generosos, así como hay sin duda también malos amigos, desleales, malagradecidos, acomodaticios o hipócritas. En principio, la idea de la distinción amigo-enemigo, a pesar de Schmitt, involucra como criterio un horizonte de comprensión específicamente moral, que concierne de modo directo con la racionalidad práctica y que, además, se subordina a sus condiciones de sentido. Es una distinción para la hermenéutica política, pero reposa sobre un fondo sustantivo de competencias morales o ideales de vida buena. Es en este sentido que la praxis de lo político no es indiferente con las creencias sustantivas de los alternantes ni consiste tampoco primariamente en la ejecución del conflicto. Por el contrario, como creo que no va a ser difícil concluir, sobre un eco de fondo conflictual, la praxis política es un quehacer incesante de reconciliación. Conclusión inevitable cuando se ha asumido la guerra como parte de la comprensión de la finitud.

En este último punto descansa una cuestión que es fundamental y que explica uno de los motivos del interés de esta contribución por ir tras el enemigo. En una genuina relación de enemistad está en curso una dimensión hermenéutica fundamental, que es la dimensión del reconocimiento. Ya se le ha prestado atención, particularmente a partir del famoso ensayo de Charles Taylor sobre el multiculturalismo, que una cierta sensibilidad con el otro debe significar que parte de la propia identidad de las comunidades está basada en un diálogo sobre la base de competencias y valoraciones que rebasan hermenéuticamente la frontera de la identidad, pero esta clase necesaria de reconocimiento es incompleta si no se opera rescatando el carácter hostil de la diferencia ${ }^{40}$. En la realidad, el diálogo intercomunitario es genuino cuando tiene lugar dentro de un horizonte narrativo conflictual, en que es precisamente el conflicto el que hace posible la significación de la idea de que el reconocimiento es un reconocimiento de la diferencia. No hay diferencia sin la comprensión de la hostilidad. Lo contrario tiene un efecto esteticista de la comprensión de la diferencia que habría que pen-

${ }^{40}$ Creo que concedo aquí una pauta para reinterpretar el fenómeno de la multiculturalidad basada en un diálogo sobre la base de competencias y valoraciones comunitarias, pero rescatando el carácter hostil de la diferencia que está ausente, por ejemplo, en autores como Taylor. No hay diferencia sin la comprensión de la hostilidad. CF. C. TAYLOR: El multiculturalismo y la politica del reconocimiento. México: FCE, 1993 (1992). 
sar más. En este sentido, las reflexiones de Charles Taylor respecto de la dimensión de la diferencia cultural adquieren dimensión de fondo cuando el diálogo se permite reconocer la hostilidad, que es la posición originaria en el ver de lo diferente. Por ello quien reconoce moralmente a un enemigo debe estar en condiciones de asignarle méritos, al menos los mismos méritos de los que se cree en obligación de estar, y apreciará sin duda que su enemigo sea leal, valiente o sagaz; verá con interés la discrepancia y, sobre todo cuando lo aprecia, le prodigará un trato privado honorable. Esto tiene un significado altamente llamativo; sugiere la idea general de que hay una "buena enemistad", que hay un modo particularmente razonable de entender al enemigo, aun cuando la tardomodernidad, enclaustrada en un refugio narcisista, sea incapaz de comprenderlo. Por ello es que, al margen de lo que pensara Schmitt al respecto, es un hecho incontrovertible que el carácter trascendental de la distinción amigo-enemigo no puede separarse de una concepción a la vez comunal y narrativa de la identidad, no sólo la del amigo y la del enemigo, sino la de ambos. La distinción supone una praxis narrativamente situada de conflictos que, como no es difícil acertar, remiten a un horizonte previo de autorreconocimiento sustantivo, a una densidad de pasado que lleva consigo la autoadscripción mutua de una historia conflictual, entendiendo por esta noción una narrativa en la que los amigos son solidarios en su identidad en la conflictiva con sus enemigos a quienes, fuera de la práctica efectiva de la violencia - que no es sino el margen extremo de la enemistad- debieran realizar su historia compartida como una hermenéutica de la coexistencia, como un ejercicio incesante de intercambio virtuoso de recíprocos respetos, que es más o menos la postura que podemos extraer de Gadamer en su intento por hacerle comprender a Jürgen Habermas la dimensión paradójicamente inhumana del presunto «humanismo" de la Ilustración $^{41}$.

41 Cf. particularmente su ensayo "Incapacidad para el diálogo" (1971). En: Verdad y Método II, op. cit., p. 263 y ss. Cf. también su "Réplica a 'Hermenéutica y crítica de la ideología', ibíd., pp. 243 y ss. Considero relevante también la polémica contra el saber administrativo en «Sobre la planificación del futuro», incluido en el mismo volumen. Hay que agregar que la crítica de Heidegger al "humanismo" en su Carta sobre el humanismo, consiste en que toda filosofía del «humanismo", siempre bajo la trama de una metanarrativa emancipatoria, presume una in-diferencia radical frente al otro. En este sentido, la Ilustración está esencialmente marcada por un desprecio por el carácter finito e historial de la condición humana, asumiendo que hay algún punto de vista privilegiado del Hombre que puede - y tal vez tenga el derecho de- juzgar a los hombres. 
El problema fundamental, el verdadero problema de fondo para encarar la cuestión hermenéutica del enemigo es su vinculación estricta con la violencia efectiva por enemistad política o la "guerra". Por ello, quien atiende el reconocimiento y la diferencia narrativa, pero descuida la guerra, prescinde de un fondo ineliminable de comprensión de la complejidad humana, bien sea simplificándola en una pureza angélica, como en Rousseau ${ }^{42}$, o escindiéndola en una esquizofrenia, como hizo Kant. Es obvio que la comprensión de lo político, en este sentido, está relacionada con una precomprensión de la naturaleza humana, y que el mundo moderno la ha simplificado en términos morales, operación que es simultánea con el proceso de olvido de la enemistad y el diálogo que, de ser un encuentro en el lenguaje de lo diferente, se convierte en un cultivar la amistad donde, puesto que no hay conflictos, es incomprensible para qué se hace uno de amigos. Se olvida con una facilidad inaudita que en la ausencia efectiva de conflictos no hay necesidades ni, por lo tanto, urgencia de comunalidad ${ }^{43}$. En cualquier caso, el horizonte narrativo de lo conflictual descansa sobre la idea de que hay un límite crítico necesario en el cual es posible el quiebre comprensivo. Una comunidad narrativa conflictual, que es lo que hay de fondo narrativo de la dicotomía schmittiana, una comunidad en la que hay intereses contrapuestos que advienen desde lo hondo de un reconocimiento ético a través del enemigo es siempre - para valerme del lenguaje de Heidegger- el "claro" de la guerra. Mientras la relación amigo-enemigo no ha recurrido a la violencia, el vínculo hostil se realiza fundamentalmente como una relación conflictual pacífica. ¿Cuál es el télos de la relación hostil? Un grande error de diagnóstico sería pensar que la relación amigo-enemigo implica la violencia, del mismo modo en que tampoco las relaciones entre amigos la excluyen. Los malos amigos, los desleales o los acomodaticios (que son amigos al fin y al cabo) son prueba de ello. Si se ha comprendido lo que quiero argumentar con la idea del claro, todas las relaciones humanas, incluso las de los amigos entre sí, se establecen sobre la misma dimensión hermenéutica conflictual cuyo límite (aunque no su esencia) es el conflicto no verbal, la oclusión del claro. El quehacer de la hostilidad no es la violencia, sino más bien su prevención, plasmada en negociaciones e intercambios y cesiones en los intereses cuya fricción originaria justifica el conflicto. Para decirlo con el térmi-

${ }^{42}$ No puedo evitar remitir al ensayo de Jacques Maritain "Jean-Jacques ou le saint de la nature", en Trois reformateurs, Luther, Descartes, Rousseau. París: Plon, 1925. Agradezco al profesor Miguel Polo alcanzarme el original.

${ }^{43}$ Cf. por ejemplo la propuesta de M. CABADA: Vigencia del amor. Madrid: San Pablo, 1994. 
no "equilibrio", que me prestaré interesadamente de Gadamer, diré que el claro de la guerra es el equilibrio pacífico sobre el fondo de los disensos ${ }^{44}$. En este sentido es que la distinción amigo-enemigo se abre en su "equilibrio" como claro efectual de la guerra, del mismo modo en que el pensamiento es el claro del hombre en la procesión misteriosa hacia la nada. Pero, ¿no es esto acaso la propia coexistencia humana misma como tal? Es la copresencia de lo diverso en tanto vinculado, es de la esencia de lo diferente en tanto frente del «nosotros» del claro. Es verdad que la dicotomía presupone una mutualidad hostil cuya procesión como evento comprensivo está respaldada en el frágil margen quebradizo de la ofuscación, pero ¿no es esto acaso otra cosa sino el acontecer de lo humano en su finitud? Salvando la diferencia de enfoque, coincido en esto plenamente con Gadamer: «El equilibrio se puede considerar como la verdadera condición de la libertad humana. Sólo cuando las fuerzas se mantienen en equilibrio puede actuar el factor del querer y el hacer humano". "Esto», agrega Gadamer, «lo sabemos desde siempre por la polítican ${ }^{45}$. De hecho, al menos para lo que concierne a la praxis política, el claro del equilibrio, con su margen de amenaza y disconformidad, es la experiencia de la finitud humana misma. Y el claro del mutuo reconocimiento, frente a la guerra, sólo se halla frente a su límite.

Como ha observado a su manera Hans-Georg Gadamer, es de una profunda sencillez de diagnóstico para la condición humana suponer que la relación racional entre grupos rivales nunca - subrayo la palabra nunca- puede estar en condiciones de virar narrativamente a la incomprensión, lo que en el ámbito de la praxis de lo político es la violencia o la guerra. Del mismo modo que lo impensado aparece como quiebre de la diferencia en el orden del pensamiento e irrumpe, el margen violento del claro pacífico puede muy bien establecerse como evento, lo cual no le resta ni racionalidad ni, mucho menos aún, humanidad. Una comprensión genuina del quehacer del claro o el equilibrio debe poder dar cuenta de equilibrio frente a qué es y en el fondo de qué se estima un equilibrio; tam-

44 En referencia al progreso de la tecnociencia y el aparente ocaso de la crítica (lo que acá llamamos heideggerianamente "pensamiento») dice Gadamer: «Esta idea de equilibrio lábil definido por nuestras condiciones vitales no es sólo una de las concepciones del orden político más antiguas [...]. El equilibrio es una nota fundamental de la vida a la que están vinculadas todas las posibilidades del ser vivo indefinidas y aún no fijadas" (H.-G. GADAMER: «Sobre la planificación del futuro" [1966], en Verdad y Método II, op. cit., p. 162).

\section{Ibidem.}


bién debe dar cuenta del extremo en que el equilibrio es indeseable, salvo que se suponga que el equilibrio es intrínsecamente deseable. Por desgracia la humanidad no avala tal aserto. Una concepción de lo político que no es capaz de dar cuenta de estas preguntas, o las refiere a categorías primarias como iirracionalidad» 0 «demencia» es incapaz de estimar el acontecer de la violencia en su dimensión humana y, justamente por esa razón, se trata de un ver inhumanamente la comprensión de la guerra, cuya condición de margen del claro la dignifica como el descanso de la paz. Detrás de esta hermenéutica del enemigo está también la afluencia misteriosa que hace de la diferencia el lugar propio del pensar. En términos de Gadamer, «son justamente las diferencias insalvables entre los pueblos, sus diferencias naturales e históricas, las que nos unen como seres humanos» ${ }^{46}$. Es un hecho histórico indeclinable que a veces el claro aparece a los pueblos como la opacidad de lo justo; desconocer esta evidente trivialidad significaría despojarnos del sentido entero del interés por la historia. Otra cosa es ya si las guerras concretas son buenas o malas, justas o injustas, aunque el margen comprensivo del juicio al respecto dependerá, curiosamente, de la propia disposición del claro, esto es, del quehacer comprensivo en la narrativa de los rivales, con todo y los rivales dentro luchando heroicamente.

Para terminar esta sección, regresemos a Gadamer. En una ocasión recuerda que no hay ningún motivo para creer que la ofuscación es imposible ni, mucho menos, que esta no pueda proceder de ambas partes, vale decir, la del amigo y la del enemigo ${ }^{47}$. Una aplicación elemental de la noción wittgensteiniana de "criterio" sugiere que, en cualquier caso, la decisión que diferencia al ofuscado fundamental se queda perdida en el claro, que no es un juez, sino la procesión conflictiva con el otro en el lenguaje. Ya que es conflictiva, carece de un momento definitivo de "verdad" que pueda identificar como culpables a los rivales. Este es el mérito de una perspectiva hermenéutica de la violencia y la guerra: es más universal, justamente, en el sentido en que Aristóteles hace de la política la disciplina primera de la autocomprensión humana. Una vez que hay ofuscación (y guerra) sólo queda apelar a que el vencedor muestre las virtudes que lo dignifican como enemigo, lo cual es ya una contingente y abismal esperanza en la misericordia. En este sentido, tras el límite de la ofuscación hay una apelación implí-

46 Cf. H.-G. GaDAMER: "Sobre la planificación del futuro», op. cit., p. 167.

${ }^{47}$ Cf. H.-G. GADAMER: «Réplica...", op. cit., pp. 263 y ss. 
cita (del vencido) de ser comprendido. No sólo es éste el origen de la clemencia, sino la indicación de que el fondo de las virtudes necesarias para la «buena enemistad" es su relación inevitable con la incomprensión como claustro que es de la finitud. ¿`No es eso humano, acaso? Y, por otro lado, ¿̨cómo negar la humanidad de la ofuscación?: Sólo pensando que no puede pensársela.

La única forma de hacer viable una interpretación contraria a la esbozada sería suponer que hay una versión comprensiva de la naturaleza de los intereses humanos, particularmente de los que expresan los enemigos, que haga de la disensión que se ofusca o bien un fenómeno frívolo (Rorty) o bien un caso psiquiátrico (¿Rawls?) o bien, bueno es decirlo, la presencia radical del mal (Kant). Recíprocamente, «nosotros» debería referirse a la comunidad de quienes normalmente no somos frívolos, malos o dementes ${ }^{48}$. Y si a esto se redujera el problema, estaríamos simplemente ante un sano narcisismo, un aliento del orgullo de la identidad y un cierto tipo de autoestima destinal. Y lo sería así, por cierto, bajo la presunción hermenéutica del otro, esto es, de la coexistencia pacífica con el enemigo dentro del claro ${ }^{49}$. Por desgracia, no es ése el caso. Como sea, la modernidad ha diagnosticado que desatender la disensión, olvidarse del otro, es justamente la característica que hace de los humanos seres racionales, de tal modo que nunca haya razones legítimas para ofuscarse. Tampoco hay razones, en realidad, para dialogar, al menos no en el sentido de una apertura lingüística ante la alteridad, pues lo otro del que dialoga, justamente por ser otro, marca su diferencia en lo impredecible, en lo impensado, parte de cuyo quehacer (o del nuestro) es la ofuscación. Sin el fondo de la ofuscación el diálogo es un habla sin destino. La modernidad, sin embargo, ha sentenciado que las guerras quedan excluidas, en una homologación ética sin trasfondo conflictual, como ocurre en un coche. Una llanta se revienta, no disiente del auto que rueda con ella. Pero ¿qué tal si el

48 C. F. MIRES: El fin de todas las guerras (un estudio de filosofia politica). Santiago de Chile: LOM Editores, 2001, cap. 10: "Las flores del mal».

49 Como parece ser la pretensión de R. Rorty en su Forjar nuestro pats. El pensamiento de izquierdas en los Estados Unidos del siglo XX. Barcelona: Paidós, 1999. Sobre el aspecto epistemológico cf. A. MACINTYRE, op. cit; ; en su relación con el pensamiento político, G. GAMIO: «Formas de vida ética y reconocimiento igualitario", en Revista Teológica Limense, vol. XXXI, n. 2, 1997, pp. 203 y ss. Dicho sea de pasada, ¿cómo es posible un "reconocimiento igualitario» con un otro impensado? Creo que es algo que ha sido pensado insuficientemente o no ha sido pensado con el otro, que al final es lo mismo. 
disenso sí existe? Lo que en realidad ocurre, si es que el enemigo olvidado no ha muerto, es que se despoja a las guerras de su naturaleza política para afincarlas en un orden exclusivamente moral, y siempre con el sospechoso expediente de la percepción hermenéutica de que nosotros somos siempre moralmente indignos del escrutinio de nuestro otro. ¿Cómo podría escudriñarnos alguien que no existe o no merece existir? Y que esta reflexión sirva de paso a una anámnesis de cómo así, bajo qué presupuestos, el enemigo se desvaneció tras el frágil escombro del crimen o la locura.

\section{Hostis Inimicorum}

Comenzamos preguntándonos si la ausencia del enemigo, si su criminalización, no sería un despojo de una parte importante de la autocomprensión humana. A estas alturas de nuestro trabajo hemos intentado argumentar que el enemigo no es sólo parte de la dimensión hermenéutica del propio reconocimiento, sino que es una copresencia necesaria para la experiencia de la política. Es más, la hostilidad ha sido descubierta como el trasfondo en cuyo horizonte se establece el claro del intercambio pacífico, la finitud del hombre cuyo destino es la coexistencia dialógica, la comprensión narrativa del otro en un intercambio virtuoso cuyo margen trágico lleva el hombre a cuestas. Pero ¿por qué la modernidad ha ocultado al enemigo? ¿Por qué lo ha olvidado? El enemigo no es nuestro prójimo, sino nuestro necesario. La procesión narrativa de la identidad se abre en el lenguaje por la intromisión hostil, pero virtuosa, de la diferencia. Es en un proceso de apertura que la diferencia acaece como la continuidad del relato de la relación con el hostil. Es gracias al enemigo que la tradición adquiere santos, héroes, profetas y sabios, sobresalientes que se mostraron en el eco del frente de su adversario, que se ennoblecieron y dignificaron mientras más elevado fue el reto de su diferencia. Entonces, ¿̨ómo así advino un mundo en que nos despojamos de quien nos urge, de aquel en cuya virtud descansa la nuestra? Creo que esta pregunta debe reducirse más bien a esta otra: ¿Por qué hemos llegado a extrañarnos del pensar de lo político, por qué lo político se ha esfumado como pensar?

La cuestión central es la concepción de la racionalidad que se manifiesta en la ausencia del enemigo. Si bien hay innumerables razones para no negar que hemos cruzado ya el umbral de salida de la modernidad, no dejan de tener razón aquellos defensores de la Ilustración que ven lo que Anthony Giddens bautizó como "tardomodernidad", la mera continuación del proyecto emancipatorio 
moderno, despojado ya de la investidura del "pensamiento fuerte" cuyas pretensiones de ultimidad se afincaban en la infinita voluntad cartesiana. Por ello una posición posmoderna frente a la tardomodernidad es más una posición reactiva que una propuesta, razón por la cual uno se pregunta si no es momento de recuperar a través del saber rememorante los recuerdos admonitorios del pensamiento reaccionario ${ }^{50}$. En un sentido bastante claro, la lógica del mercado y la globalización tecnológica e informática parecen ir acompañadas de una cierta concepción de la acción política y el poder que ha demostrado su vigencia justamente bajo el auspicio del poder inevitable (y destinal) de la tecnociencia ${ }^{51}$. Es además un hecho innegable que somos herederos de un proyecto normativo que procede de la Ilustración, una de cuyas características es la lectura progresiva del pasado como epopeya de su propia apoteosis, de tal modo que el establecimiento sustantivo de la Ilustración compromete como destino a los portadores de su narrativa ${ }^{52}$. Es en este sentido específico que la emancipación se hace compañera destinal de la tecnociencia y que, pese a quien le pese, su expansión significa un poder que inexorablemente adquiere el carácter único de la irresponsabilidad técnica, ensombreciendo la decisión sobre los fines en la anomia anónima del mercado y la prensa ${ }^{53}$. Curiosamente, la idea de emancipación habría logrado un control efectivo de los medios de control social, a través del saber de la tecnociencia, y sería ella misma la creadora de una forma inapelable de consenso que, como alguna vez dijera el propio Gadamer, es en realidad "un consenso falso" " No es el resultado de un mundo tejido por el uso comprensivo del lenguaje, sino de un lenguaje comprensivo creado por la técnica y la prensa de masas para jus-

so Sobre la "reacción" y la posmodernidad cf. G. VATTIMO: "Posmodernidad: ¿Una sociedad transparente?", en Umbral, n. 9, abril 1997, pp. 21 y ss. Sobre el fin de lo moderno, también G. VATTIMO: El fin de la modernidad: nihilismo y hermenéutica en la cultura posmoderna. Barcelona: Gedisa, 2000, pp. 12 y ss.

${ }^{1}$ Cf. H. J. MEYER: La tecnificación del mundo: origen, esencia y peligros. Madrid: Gredos, 1966, especialmente cap. 7.

52 En este sentido, dice Carlos Thiebaut (Los limites de la comunidad. Madrid: Centro de Estudios Constitucionales, 1992, p. 13): “El liberalismo acentúa el carácter históricamente inevitable de los valores y de las estrategias racionales que se encuentran en el programa liberal".

53 Cf. el ensayo H.-G. GADAMER: "Los límites del experto", en La herencia de Europa. Barcelona: Península, 1990 (1989), pp. 127 y ss. Ensayo recomendable para expertos en humanidad y pedagogos «cívicos». Cf. A. H. Colombo: Democracias sin fundamento. Buenos Aires: Trama editorial, 2001, cap. 13.

54 Cf. H.-G. GADAMER: "La incapacidad para el diálogo», en Verdad y Método II, op. cit., p. 203. 
tificarse a sí misma como tarea humanitaria y liberadora más allá de la reflexión y del carácter contingente de la humanidad.

No es momento de reiterar - una vez más - que las metanarrativas han perdido su eficacia. Tampoco que la decadencia de la epistemología como modo privilegiado del pensar, en la segunda mitad del siglo pasado, ha significado el vaciamiento ontológico de ese proyecto. Pero se trata de indicadores reales que sugieren la prioridad ontológica del saber de la tecnociencia sobre la comprensión humana. En la metanarrativa de la Ilustración el saber de las luces, que es el conocimiento del mundo bajo el patrón de lo moderno, encuentra su enemigo en el saber tradicional, en el conocimiento que Gadamer bien ha reconocido en términos de tradición y que no es otra cosa que la recepción comprensiva de la experiencia de la finitud como un habitar en el lenguaje. En algún sentido la experiencia de nuestra metanarrativa emancipatoria es la lucha totalizadora y omnipotente contra la finitud ${ }^{55}$. Es el autoafianzamiento de un cierto tipo de autocomprensión en la omnipotencia. Como hace notar Gadamer, es parte fundamental de la comprensión de lo moderno, y peculiarmente de las pretensiones emancipatorias de "lo ilustrado", el decidir sobre lo otro y el Otro a partir de la presunción de que se posee un conocimiento privilegiado de lo absoluto. Es aquí donde queríamos llegar. La mera idea de que hay una adhesión culturalmente popular a admitir un "pensamiento único" es síntoma de un autodespojo que es la secuela de la lucha contra la finitud y que significa que la agenda de olvido del enemigo es, en su dimensión más densa y profunda, la licencia del hombre para olvidarse de sí mismo, para hundirse en el abismo de la ausencia de su propia finitud. Quizá no sea un exceso recordar que, si hubiera que hacer un diagnóstico de la Ilustración, bien cabría reiterar el carácter narcisista de su narración como proyecto. La Ilustración es un proyecto patológico de humanidad ${ }^{56}$, que bajo la excu-

ss "La finitud del hombre, según la ha definido Heidegger, es quizás el golpe de muerte asestado a la ideologia del lluminismo, pues reconocer esta finitud equivale a reconocer que el hombre siempre existirá en la falta de verdad como en la verdad" (W. BARRETT: El hombre irracional, estudio del existencialismo. Buenos Aires: Siglo XX, 1967, p. 299. Cf. caps. I-II y Apéndice I). En H.-G. Gadamer cf. por ejemplo el ensayo "La continuidad de la historia y el instante de la existencia" (1965), en Verdad y Método II, op. cit., p. 139.

${ }^{56}$ Cf. sobre el carácter patológico de la Ilustración, R. KOSELLECK: Crítica y crisis del mundo burgués. Madrid: Rialp, 1965 (1959). También la interpretación dicotómica de la comprensión histórica humana en R. KOSELLECK y H.-G. GADAMER: Historia y hermenéutica. Barcelona: Paidós, 1997, pp. 70 y ss. 
sa paranoide de la emancipación contra la tradición, pretende que el finito portador del estandarte de la modernidad es un ser omnipotente, que tiene bajo su control a lo otro y lo absorbe bajo los parámetros de un diálogo que no es lenguaje, o bien que, si lo otro hace la diferencia, entonces lo hace merecedor de la muerte $^{57}$. Es misión de la filosofía - y en esto coincido con Gadamer - mantenerse alerta frente a la miseria de la Ilustración, como frente a cualquier aliento de pretensión de verdad totalizadora y excluyente de la diferencia: "tener siempre presente la propia finitud y el condicionamiento histórico". En este sentido, ya que la Ilustración es el consenso del final de la modernidad, y el trasfondo de la violencia hermenéutica contra la dignidad del enemigo, convengo en que la tarea fundamental del filósofo es en el umbral de una modernidad inextinguible «resistir a la autoapoteosis de la Ilustración»"

En una versión comprensiva de lo político que se establece desde el lenguaje, este adquiere siempre la forma del alegar. Se manifiesta como un demandar en favor y en contra sobre un fondo común en que el mensaje «otro» del otro es siempre otro absolutamente, esto es, que se reserva el margen de lo impensado ${ }^{59}$. Es, como bien ha notado Gadamer, en la procesión de la finitud en su discurrir narrativo, un incesante alegato de sí mismo frente al otro, un alegato que, ante la presencia de lo otro como otro, es de la esencia de la comprensión de sí mismo. "Es realmente una tarea gigantesca", dice Gadamer en un ensayo recogido en La herencia de Europa, «la que debe desempeñar cada ser humano en cada momento. Se trata de controlar su parcialidad de tal modo que el Otro no sea invisible o no permanezca invisible. No es fácil comprender que se puede dar razón al Otro, que uno mismo y los propios intereses pueden no tener razón... Tenemos que aprender a respetar al Otro y a lo Otro. O, lo que es lo mismo, tenemos que aprender a no tener razón" ${ }^{60}$. Y

57 Aunque los diagnósticos psicoanalíticos no son lo más apropiado, aquí se trata de alegar en favor del enemigo para comprender su desalojo. Es un alegato judicial y, como tal, admite todo tipo de razones. Por otro lado, hay que señalar que la absorción o la muerte del otro son parte de la definición de lo que Rosenfeld llama "narcisismo negativo». Cf. H. RosENFELD: Impasse and Interpretation. London: Routledge, 1987.

58 Cf. H.-G. GADAMER: “La verdad en las ciencias del espíritu» (1953), en Verdady Método II, op. cit., p. 48.

59 En el sentido de R. OTTO: Le Sacré, l'élément non-rationnel dans l'idée du divin et sa relation avec le rationnel. Paris: Payot, 1949, pp. 46 y ss.

60 Cf. H.-G. GADAMER: "La diversidad de Europa", en La herencia de Europa, op. cit., p. 37. Cf. también H.-G. GADAMER: "Texto e interpretación" (1984), en Verdad y Método II, op. cit., pp. 324-325. 
esto es verdad incluso y a pesar de que lo otro haya sido olvidado bajo la forma del enemigo. Para el quehacer narcisista de la modernidad, suelta ya del fundamento y con la extensión global de la técnica, la agenda de olvidar al otro tiene que consistir en la negación del enemigo como un alguien divergente, como disidencia que suscita el pensamiento, al menos el pensamiento que, como lo hace en efecto la tradición, atiende la disidencia como origen de su propia sustancia ${ }^{61}$. Curiosamente, la indiferencia completa hacia lo otro en que consiste su olvido no altera la procesión del otro, pues el otro es un necesario, un imprescindible para la autocomprensión narrativa, incluso si lo es para ser objeto de olvido o extirpación. Por ello el olvido de la humanidad del enemigo distorsiona las condiciones de la propia comprensión humana de quienes le niegan el honor virtuoso y, más aún, tiende a sustituirla por un tipo de violencia sin reconocimiento, esto es, una violencia intrínsecamente perversa ${ }^{62}$. Insistamos: Estamos ante una violencia que, a diferencia del trasfondo hermenéutico de la enemistad, es ciega ante el carácter moral del otro y lo despoja de su condición humana. Una violencia que es capaz de ver en su propio ejercicio, virtualmente, una extensión del carácter perentorio omnipotente de la exigencia de la técnica, no otra justicia que la infinita, es decir, una justicia patológica, narcisista, inhumana e injusta.

Uno de los elementos centrales de la autocomprensión de lo político en expectativa de la tardomodernidad es el consenso, algo curioso, de que el fin fáctico de las "grandes oposiciones" de los bloques ideológicos significa que la política se identifica con un quehacer institucional único, con un programa único de praxis política que corresponde a un pensamiento político cuya esencia es el programa de la Ilustración ${ }^{63}$. Tenemos, como destino, la "intuición" del carácter perentorio del programa ilustrado ${ }^{64}$. Habría tal vez primero que preguntar de quién y en qué circunstancias se da este consenso, por qué es tan perentorio y

61 Aquí tengo en cuenta la noción de Green sobre el narcisismo que se vincula con la ausencia temprana de la madre, que se refleja luego especularmente como un quehacer con el otro como ausente. Cf. A. GREEN: Narcisismo de vida, narcisismo de muerte. Buenos Aires: Amorrortu, 1993.

${ }^{62}$ Cf. en H.-G. Gadamer particularmente su ensayo “¿Qué es la verdad?», en Verdad y Método $I I$, op. cit.

${ }^{63}$ Cf. por ejemplo, y para citar un libro serio, S. Toulmin: Cosmópolis, el trasfondo de la modernidad. Barcelona: Península, 2001 (1990).

${ }^{64}$ Cf. C. THIEBAUT: Vindicación del ciudadano, un sujeto reflexivo en una sociedad compleja. Barcelona: Paidós, 1998, pp. 273, 278-279, donde el autor confiesa que apela a "nuestra intuición" como suscriptores de tradiciones democráticas. 
por qué habría que considerarlo como fuente de alguna "intuición" o un consenso irrenunciable. Por desgracia, justamente una de las desventajas de este «consenso" es que nos inhibe de hacer las preguntas que subyacen a la crisis, a la irrupción destinal del enemigo que los suscriptores de la emancipación parecen incapaces de reconocer. Esta incapacidad es, precisamente, el síntoma manifiesto de que, como diría MacIntyre, "algo anda fundamentalmente mal»" ${ }^{65}$. El argumento de la intuición es más o menos como sigue: Nuestro consenso se ha vuelto normativo porque es. Como es, tiene carácter destinal y, desde el fondo de nuestra urgencia, exige que el pensamiento ceda su lugar al silencio automático del experto anónimo y la máquina irreflexiva: ¡Hagamos, pues, la guerra! ${ }^{66}$. El «pensamiento único", la globalización y el mercado reclaman al otro orgullosos, paradójicamente, junto con Kant (y con Rorty): «¡Discutid todo lo que queráis, pero obedeced!»" ${ }^{67}$.

Por algún motivo no es difícil sospechar que la intuición es mala amiga y peor consejera. Una intuición frente a cuyo otro no se dice nada es, sin duda, el más penoso expediente de la racionalidad. Esta es la intuición de las modernas sociedades opulentas de pensamiento único cuyo "consenso" ha adquirido en el crepúsculo epocal de la modernidad la obsesión omnipotente por una paz mercantil que suprime a los osados que desean asaltar con su presencia el orden de negocios del templo. ¡Cuán inhumano es todo esto! En la medida en que se trata de un desafío para el pensar es que dice Macintyre que, cuando vemos a los ilustrados apelar a la intuición, sin duda, es porque algo anda fundamentalmente mal en el orden de sus justificaciones ${ }^{68}$. Al parecer, el pensamiento sobre lo que anda mal es algo que se reserva el enemigo, olvidado del otro lado de ese "falso consenso» que señala Gadamer y que limita en la violencia hermenéutica el apagamiento de la tardomodernidad. Y es así que el enemigo, el disidente, está allí

${ }^{65}$ Dice MacIntyre que cuando se apela a la intuición, sin duda, es "porque algo anda fundamentalmente mal». Cf. A. MACINTYRE: After virtue. Notre Dame: Notre Dame University Press, 1984 , p. 69.

${ }^{66}$ Dice I. Kant ("Comienzo de la historia humana", en Filosofia de la historia. Buenos Aires: Nova, s/f, p. 133): «En el grado de cultura en que todavía se halla el género humano, la guerra es un medio insalvable para extender la civilización [i!], y sólo después que la cultura se haya cumplido [Dios sabe cuándo] nos será posible una paz perpetua, y se tornará posible». Mensaje más claro no podría tener el enemigo.

${ }^{67}$ Cf. el ensayo de Kant "¿Qué es la Ilustración?", recogido en op. cit. p. 60.

${ }^{68}$ Cf. A. MACINTYRE: After virtue, loc. cit. 
siempre, urgido y olvidado en lo hondo de la violencia de la Ilustración, enclaustrado en una oscura faz tras la verdad objetiva de una cárcel o en un manicomio, padeciendo desempleo o migrando errante sin patria para invitar a esa Ilustración, tal vez, aplastado en los quebrados tiestos de una Arabia insondable, al reto de pensar. Un reto inevitable para seguir siendo humanos, al menos en lo que respecta a nuestra pobre e inextinguible finitud. Un reto tan grande como lo es la diferencia, el enemigo, el conflicto y, tras ellos, la justicia de la guerra. 